\title{
Vocational decision making by sixty spinal cord injury patients
}

\author{
R Crisp MAPsS, \\ Rehabilitation Counsellor, Commonwealth Rehabilitation Service, Australia.
}

Sixty persons with spinal cord injury completed the My Vocational Situation (MVS) questionnaire developed by Holland, Daiger and Power. ${ }^{1}$ The MVS was designed to identify problems related to vocational decision making, ie lack of vocational identity, lack of occupational information, and the presence of environmental or personal barriers to a chosen occupational goal. As expected, more problems were reported by unemployed persons than by employed persons, and by those who reported lower levels of psychological well being. MVS scores were not mediated by age, time since injury or severity of injury.

Key words: spinal cord injuries; outcome; vocational rehabilitation.

\section{Introduction}

A recent review of the literature ${ }^{2}$ identified numerous demographic, medical and epidemiological factors associated with the employment status of people with spinal cord injury (SCI). While few generalisations can be made from the SCI literature, it seems clear that the vocational outcome depends upon the rehabilitation client having sufficient understanding of self, knowledge of the world of work, and the resources to cope with potential social and physical barriers to employment.

The purpose of this paper is (1) to analyse the self reported vocational decision making skills of persons with SCI, and (2) to identify the specific types of vocational rehabilitation services that they require. Central to the design of this study is the experimental diagnostic scheme developed by Holland, Daiger and Power ${ }^{1}$ and known as $M y$ Vocational Situation (MVS). The MVS was designed to identify 3 important aspects of vocational decision making:

1 Vocational identity, ie the extent to which an individual possesses clear vocational goals and self perceptions which enable relatively untroubled decision making and confidence in making good decisions in the face of 'inevitable environmental ambiguities'. ${ }^{1}$

Correspondence: 67 Bayswater Road, Croydon 3136, Australia.
2 Occupational information, ie the client indicates whether he or she needs occupational information.

3 Barriers, ie the client's perceived external and personal obstacles to a chosen occupational goal.

The MVS appears to be useful for identifying (1) persons with a poor sense of identity who need work experience, training and personal counselling; and (2) those with a clear sense of identity, but who need career and labour market information. It is potentially an effective time saving device to assign an individual to a particular type of counselling service. Further, rehabilitation counsellors can encourage persons with disabilities to use the MVS as a 'self exploration device' instead of relying upon advice and guidance from a counsellor. In research, the MVS may be useful for investigating career stability and vocational development ${ }^{1}$ and for evaluating the effectiveness of vocational rehabilitation programmes. $^{3}$

In the present study, the relationship between MVS scores, several demographic factors and general psychological adjustment was examined. The demographic factors were employment status, age, time since injury and severity of injury; and psychological adjustment was measured by two standardised (life satisfaction and depression) scales utilised by Schulz and Decker ${ }^{4}$ in their study of long term adjustment to SCI. Since the major interest of 
many past studies has been in the process of coping immediately following the onset of SCI, the present study focused upon persons who had lived with SCI for 5 years or longer.

\section{Method}

\section{Respondents}

For inclusion in this study a person was required to have had a traumatic spinal cord injury for 5 years or longer, be resident in a non institutional community setting, and be willing to participate. Respondents were located through organisations which provide services for persons with SCI in Victoria, Australia, namely the Austin Hospital, Commonwealth Rehabilitation Service, and the self help groups 'AQA' and 'Paravics' Sports Club. The research instruments were administered in the homes or workplaces of the respondents. There were no telephone interviews.

The sample consisted of 60 persons with traumatic SCI. They were predominantly Caucasion $(98 \%)$ and male $(83 \%)$. The ages of respondents ranged from 19 to 55 years; mean age and median was 36.2 and 34.7 respectively. Time since injury (TSI) ranged from 5 to 33 years with a mean TSI of 11.9 , median 9.6 and mode 7 years. Motor vehicle $(58 \%)$ and diving (18\%) accidents were the major causes of SCI in this group. Persons with paraplegia and quadriplegia each accounted for $50 \%$ of this sample, and $17 \%$ of all respondents had incomplete injuries. Twenty-eight $(47 \%)$ respondents were engaged in full or part time employment; 24 $(40 \%)$ were married, including 2 persons in defacto relationships; and all but one respondent lived in an uban area.

\section{Instruments}

The MVS $^{1}$ is a brief self administered and hand scored form which consists of: 18 true-false vocational identity items, 4 yes-no occupational information items and 4 yes-no barriers items. In all instances, the high score is in the favourable direction. Holland et al $^{1}$ reported internal consistency reliabilities of $.86-.89$ for the vocational identity scale (.83 in the present study), .39-.79 for the occupational information scale (.64 in the present study), and .23-65 for the barriers scale (.34 in the present study). As the occupational information and barriers scales have a relatively low degree of internal consistency, they are regarded as useful checklists rather than as homogeneous scales. Estimates of construct validity were also provided by Holland et $a l^{1}$ and Lucas, Gysbers, Buescher \& Heppner. ${ }^{5}$

Holland et al ${ }^{1}$ suggested that the vocational identity scale may also be a general adjustment scale. To enable an evaluation of the general psychological adjustment of this sample, 2 standardised measures of adjustment were also administered:

1 Life satisfaction. ${ }^{6}$ This scale consists of 18 items and 3 factors: zest for life as opposed to apathy, optimistic mood tone, and congruence between desired and achieved goals. Internal consistency reliability was .72 in the present study and .76 in Schulz and Decker's ${ }^{4}$ study.

2 Depression. The CES-D scale ${ }^{7}$ consists of 20 items and scores range from 0 to 60 with scores of 16 or higher reflecting greater severity of depressive symptoms. Internal consistency reliability in this study was .88 , and above .80 in other studies. ${ }^{4.7}$

\section{Results}

Descriptive analyses

The 12 most frequently answered MVS items are listed in rank order in Table I. The data in Table I provide an indication of the career planning views and vocational rehabilitation needs of this group.

Mean scores on the 3 sections of the MVS in this study were compared with those reported in 2 other studies. ${ }^{1.5}$ As shown in Table II, the means were similar in both the SCI group and some other non disabled groups.

The mean life satisfaction score (9.97) was similar to that reported in other studies of SCI and non disabled populations; ${ }^{4}$ likewise, the mean depression score (9.25) was similar to other $\mathrm{SCI}^{4}$ and non disabled groups. $^{7}$ 
Table I Ranking of MVS items

\begin{tabular}{|c|c|c|c|c|}
\hline & & & $\%$ ans & ng true \\
\hline $\mathrm{Qu}$ & stion* & Ranking & $\begin{array}{l}\text { Employed } \\
\mathrm{n}=28\end{array}$ & $\begin{array}{l}\text { Unemployed } \\
\mathrm{n}=32\end{array}$ \\
\hline 19 & $\begin{array}{l}\text { I need more information about em- } \\
\text { ployment opportunities }\end{array}$ & 1 & 39 & 62 \\
\hline 14 & $\begin{array}{l}\text { I would like to increase the number of } \\
\text { occupations I could consider }\end{array}$ & 2 & 43 & 56 \\
\hline 15 & $\begin{array}{l}\text { My estimates of my abilities and tal- } \\
\text { ents vary a lot from year to year }\end{array}$ & 3 & 36 & 56 \\
\hline 3 & $\begin{array}{l}\text { I am uncertain about the occupations I } \\
\text { could perform well }\end{array}$ & 4 & 29 & 59 \\
\hline 8 & $\begin{array}{l}\text { Making up my mind about a career } \\
\text { has been a long and difficult problem } \\
\text { for me }\end{array}$ & 5 & 29 & 50 \\
\hline 4 & $\begin{array}{l}\text { I don't know what my major strengths } \\
\text { and weaknesses are }\end{array}$ & 6 & 32 & 44 \\
\hline 11 & $\begin{array}{l}\text { I don't know enough about what } \\
\text { workers do in various occupations }\end{array}$ & 7.5 & 36 & 37 \\
\hline 12 & $\begin{array}{l}\text { No single occupation appeals strongly } \\
\text { to me }\end{array}$ & 7.5 & 32 & 41 \\
\hline 5 & $\begin{array}{l}\text { The jobs I can do may not pay enough } \\
\text { to live the kind of life I want }\end{array}$ & 9.5 & 36 & 34 \\
\hline 20 & $\begin{array}{l}\text { I am uncertain about my ability to } \\
\text { finish the necessary education or train- } \\
\text { ing }\end{array}$ & 9.5 & 25 & 44 \\
\hline 13 & $\begin{array}{l}\text { I am uncertain about which occupation } \\
\text { I would enjoy }\end{array}$ & 11.5 & 25 & 41 \\
\hline 16 & $\begin{array}{l}\text { I am not sure of myself in many areas } \\
\text { of life }\end{array}$ & 11.5 & 21 & 44 \\
\hline
\end{tabular}

*Questions 3-5, 8, 11-16 represent the vocational identity scale; question 19: occupational information; question 20: barriers.

\section{Correlational analyses}

Vocational identity was significantly related to the standard measures of psychological adjustment, ie positively related to life satisfaction $(r=.38, p<.01)$ and negatively associated with depression $(r=-.38$, $p<.01)$.

Table III indicates that these 3 measures of adjustment were not significantly related to age, time since injury or severity of injury. Employment status (employedunemployed) was positively associated with vocational identity and life satisfaction, but not depression.

\section{Discussion}

Problems of vocational decision making were mainly characterised by lack of infor- mation about employment opportunities, uncertainty about vocational and educational abilities, lack of knowledge of occupations and uncertainty in many (avocational) areas of life.

The level of psychological adjustment of the present study's SCI group was similar to the general population. While persons with SCI do have special needs and deal with problems not faced by non disabled persons, they are not necessarily burdened psychologically by their disability. Further, they may have reached a level of vocational identity before and/or after the onset of disability which enables them to be more decisive and confident in decision making than, for example, a young non disabled student or adult who is undergoing career or personal counselling. 
Table II Comparisons of mean scores on vocational identity (VI), occupational information (OI) and barriers (B) scales of the MVS

\begin{tabular}{lrcc}
\hline Sample & VI & OI & B \\
\hline Present study & 12.1 & 2.5 & 3.2 \\
Non disabled & 11.7 & 2.6 & 3.2 \\
$\quad$ full time workers* & 9.5 & 2.6 & 3.5 \\
$\quad$ graduate students/faculty* & 1.0 & 3.3 \\
$\quad$ first year university & 9.5 & 0.9 & 2.7 \\
$\begin{array}{l}\text { students** } \\
\text { adults seeking career }\end{array}$ & & & \\
\hline
\end{tabular}

* Data from Holland, Daiger \& Power. ${ }^{1}$

** Data from Lucas, Gysbers, Buescher \& Heppner. ${ }^{5}$

Table III Correlates of vocational identity (VI). life satisfaction (LS) and depression (D)

\begin{tabular}{lccc}
\hline & VI & LS & D \\
\hline VI & & $.38^{* *}$ & $-.38^{* *}$ \\
LS & & & $-.60^{* * *}$ \\
Employment status & $.29^{*}$ & $.39^{* *}$ & -.16 \\
Age & .21 & .12 & .00 \\
Time since injury & -.03 & .04 & -.13 \\
Severity of injury & .05 & .19 & -.01 \\
\hline
\end{tabular}

$* p<.05 \quad * * p<.01 \quad * * * p<.001$

Not surprisingly, employed respondents had more clearly defined vocational goals and more positive self perceptions than the unemployed respondents. They may also have been less adversely predisposed to environmental barriers to employment, eg financial disincentives, a major barrier to employment for some persons with SCI. ${ }^{2.8}$
However, the social and economic factors which may inhibit vocational decision making were not clearly identified in this study. The barriers scale of the MVS was not sufficiently useful for this purpose. Further rehabilitation research which focuses on both individual, social and economic factors is required.

The positive relationship between life satisfaction and employment status may reflect the economic and psychosocial benefits that can be linked with being employed. That is, the employed respondents probably had better financial resources to enable them to be mobile and involved in satisfying social activities than those who have remained unemployed. However, depressive symptoms were not significantly greater among those who were unemployed.

It is important to appreciate that the MVS is not simply an instrument for clinical assessment. Rather, the focus is on 'assessment and exploration of opportunities and constraints'.' These 2 activities may be accomplished with the MVS or a similar inventory such as the career decision scale. ${ }^{10}$ Although the administration of either scale is simple, the latter is perhaps restricted to surveying career indecision among students in educational settings. For a diverse group of individuals with SCI, the MVS may help to identify the need for a particular type of counselling service. Individuals with a poor sense of vocational identity may explore their options via interest inventories (effectively used, for example, by Rohe and Athelstan ${ }^{11.12}$ ), counselling and work training. Those with a clear sense of identity may simply need career and labour market information.

\section{References}

1 Holland JL, Daiger DC, Power PG (1980) My Vocational Situation. Consulting Psychologists Press, California.

2 Crisp R (1990) Return to work after spinal cord injury. J Rehabil 56 (1): 28-35.

3 Farley RC. Schriner KF, Roessler RT (1988) The impact of the occupational choice strategy on the career development of rehabilitation clients. Rehabil Psychol 33: 121-125.

4 Schulz R, Decker S (1985) Long-term adjustment to physical disability: the role of social support, perceived control. and self-blame. J Personality Soc Psychol 48: 1162-1172.

5 Lucas EB, Gysbers NC, Buescher KL, Heppner PP (1988) My vocational situation: normative, psychometric, and comparative data. Measure Eval Counseling Dev 21: 162-170.

6 Adams DL (1969) Analysis of a life satisfaction index. J Gerontol 24: 470-474.

7 Radloff L (1977) The CES-D scale: a self-report depression scale for research in the general population. Applied Psychol Measure 1: 385-401. 
8 Trieschmann RB (1988) Spinal Cord Injuries: Psychological, Social and Vocational Rehabilitation. 2nd ed. Demos, New York.

9 Gottfredson LS (1986) Special groups and the beneficial use of vocational interest inventories. In: Walsh WB, Osipow SH, eds. Advances in Vocational Psychology: The Assessment of Interests. Consulting Psychologists Press, California.

10 Osipow SH (1987) Career Decision Scale Manual. Psychological Assessment Resources, Florida, USA.

11 Rohe DE, Athelstan GT (1985) Change in vocational interests after spinal cord injury. Rehabil Psychol 30: 131-143.

12 Rohe DE, Athelstan GT (1982) Vocational interests of persons with spinal cord injury. J Counseling Psychol 29: 283-291. 